OPEN ACCESS

Edited by:

Andrew S. Day,

University of Otago, New Zealand

Reviewed by:

Marc A. Benninga,

Amsterdam University Medical

Center, Netherlands

Hazhir Javaherizadeh,

Ahvaz Jundishapur University of

Medical Sciences, Iran

*Correspondence.

David Avelar Rodriguez davidavelar1@Outlook.com

Specialty section

This article was submitted to Pediatric Gastroenterology,

Hepatology and Nutrition,

a section of the journal

Frontiers in Pediatrics

Received: 16 August 2020 Accepted: 21 December 2020

Published: 20 January 2021

Citation:

Avelar Rodriguez D, Popov J, Ratcliffe EM and Toro Monjaraz EM (2021) Functional Constipation and

the Gut Microbiome in Children:

Preclinical and Clinical Evidence.

Front. Pediatr. 8:595531.

doi: 10.3389/fped.2020.595531

\section{Functional Constipation and the Gut Microbiome in Children: Preclinical and Clinical Evidence}

\author{
David Avelar Rodriguez ${ }^{1,2 *}$, Jelena Popov ${ }^{3}$, Elyanne M. Ratcliffe ${ }^{4}$ and \\ Erick Manuel Toro Monjaraz ${ }^{1}$
}

${ }^{1}$ Department of Pediatric Gastroenterology and Nutrition, Instituto Nacional de Pediatría, Mexico City, Mexico, ${ }^{2}$ Department of Pediatrics, The Hospital for Sick Children, Toronto, ON, Canada, ${ }^{3}$ College of Medicine and Health, University College Cork, Cork, Ireland, ${ }^{4}$ Division of Gastroenterology and Nutrition, Department of Pediatrics, McMaster University, Hamilton, ON, Canada

Functional constipation is a common condition in childhood with significant impact on patients' quality of life and on health care resources. Functional constipation is characterized by decreased bowel movements and/or hard stools, which cause significant distress for children and their caregivers. While the term "functional" may imply the absence of organic causes with a focus on behavioral aspects, $40 \%$ of children continue to have symptoms beyond conventional management with one in four children continuing to experience constipation into adulthood. The refractory and chronic nature of constipation highlights the importance of considering a range of pathophysiological mechanisms, including the potential role of the gut microbiome. In this review, we provide an overview of preclinical and clinical studies that focus on the potential mechanisms through which the gut microbiome might contribute to the clinical presentation of functional constipation in pediatrics.

\section{Keywords: functional constipation, childhood constipation, gut microbiota, gut microbiome, functional gastrointestinal disorders}

\section{INTRODUCTION}

Functional constipation (FC) is a common condition in childhood (1) which causes significant distress and impairs the quality of life of children and parents (2). FC also causes a significant burden on healthcare resources through the frequent use of costly medical services $(3,4)$. FC is characterized by decreased bowel movements and/or hard stools and can be complicated by retentive fecal incontinence (5). FC is a clinical entity that can be diagnosed based on the child's bowel habits, signs and symptoms, and according to the Rome IV criteria (6-8). In equivocal cases or the presence of red flags, ancillary investigations can be used to rule out organic causes such as Hirschsprung's disease, anorectal malformations, pediatric intestinal pseudo-obstruction, hypothyroidism, and celiac disease (8).

The term "functional" may imply the absence of an organic etiology and emphasizes behavioral factors (see below) as the main drivers of the disease $(6,7)$. However, the fact that approximately $25 \%$ of children continue to experience symptoms in adulthood (9) and only $60 \%$ of children are symptom-free after 6-12 months, (10) suggests the involvement of other pathophysiological mechanisms. Non-adherence to pharmacotherapy has previously been cited as one important factor contributing to poor outcomes (11). More recently, the gut microbiome has begun gaining increasing attention in guidelines (8) and expert reviews $(12,13)$. However, there is seldom 
elaboration on how the gut microbiome may contribute to the pathophysiology of pediatric FC as the current evidence is limited and often contradictory. Therefore, this state-of-the-art review aims to explore and summarize the possible mechanisms of interaction between the gut microbiome and FC in children, based on data from preclinical and clinical studies.

\section{EPIDEMIOLOGY AND ASSOCIATED FACTORS}

The true prevalence of FC in children is difficult to determine due to the important limitations of study methodologies, such as population sampling, study setting, data collection, and study homogeneity $(14,15)$. The most recent systematic reviews and meta-analysis (1) have estimated a global pooled prevalence of 9.5\% (0.5-32\%), with significantly more affected children in America and Europe than in Asia. These findings differ from a prior systematic review which reported a mean prevalence of $16 \%$ (16). A recent observational study of $>1,100$ Sri Lankan children reported a prevalence of $8 \%$ and increased risk for children living in urban areas and children who are underweight for their age (17). FC in children does not appear to have a sex or age predilection $(1,15,17)$.

Certain factors have been associated with an increased risk of developing FC. Childhood traumas such as peer bullying and verbal/physical abuse within the family have been suggested $(1,18,19)$, however the evidence is contradictory (20). Children with difficult temperaments, emotional/behavioral problems, and frequent temper tantrums may also be more likely to experience constipation and soiling (21). Socioeconomic status does not appear to be a significant factor $(1,17,20)$. However, dietary habits and physical activity may play an important role as children with FC report lower intake of fruits and vegetables, increased consumption of fast foods, and lower physical activity levels (1). At present, the true cause-effect nature of these interactions remains unclear due to the designs of observational studies and their inherent risk of bias.

\section{PATHOPHYSIOLOGY}

The pathophysiology of FC is multifactorial, involving a complex interplay between behavioral factors and alterations in the gut microbiome and gastrointestinal motility.

\section{Behavioral Aspects}

The trigger for FC is often the painful passage of hard stools, which causes the child to enter a vicious cycle of withholding stools and thus worsening constipation $(6,7)$. In a recent systematic review (22), 17 unique behaviors were described to be associated with functional defecation disorders, including behaviors related to fear or anxiety concerning defecation or sitting on the toilet. The most commonly reported behavior was described as "stool toileting refusal," which is a likely contributor to the vicious cycle of withholding behaviors (22).

\section{The Gut Microbiome}

The gut microbiome is composed of trillions of microorganisms and is considered the "body's virtual organ" given its importance in maintaining host homeostasis (23). Disruptions in the gut microbiome are often referred to as "dysbiosis" and have increasingly been associated with a number of disease states in children (24), including functional gastrointestinal disorders such as irritable bowel syndrome (25-27) and constipation (28-30).

\section{Bacterial Colonization in Early Life}

Neonatal and infancy periods are strongly influenced by the mode of delivery and feeding (23). Infants born via vaginal delivery exhibit microbiome profiles resembling the maternal vaginal flora, dominated by Lactobacillus, Prevotella, or Sneathia spp, indicating direct vertical transmission. In contrast, cesarean section infants exhibit higher levels of Staphylococcus, Corynebacterium, and Propionibacterium spp. (31), which are common components of skin flora. While formula-fed infants harbor a wider diversity of bacteria, breastfed infants exhibit greater interactions between microbial and host genes, indicating higher levels of bioactive compounds in breastmilk compared to formula milk (32). Furthermore, in contrast to the traditional belief that the introduction of solid-foods drives maturation of the infant microbiome, recent evidence suggests that it may be the cessation of breastfeeding which has the greatest impact on promoting microbial community shifting to resemble an adult phenotype (33). Interestingly, children with FC are more likely to have a history of delivery via cesarean section and a shorter duration of breastfeeding compared to controls with no history of constipation (29). This suggests that early gut microbiome insults [e.g., cesarean delivery, antibiotic use, formula-feeding/shorter duration of breastfeeding, or intrapartum antibiotic administration (34)] may increase the risk of developing FC later in life. For instance, children with a history of necrotizing enterocolitis, most of whom are premature and are virtually all treated with prolonged courses of antibiotics, have a higher incidence of FC compared to healthy children (35).

\section{Evidence From Animal Models}

Preclinical data from germ-free (GF) and antibiotic-treated animal models have supported the role of the gut microbiome in regulating gastrointestinal motility through complex neuroendocrine and metabolic mechanisms. Microbial-derived metabolites such as tryptamine (36) and short-chain fatty acids (SCFAs), $(37,38)$ have been shown to promote intestinal motility. Tryptamine, a monoamine with a similar structure to serotonin (5-HT), was shown to increase anion and fluid secretion and stimulate whole-gut transit through activation of the 5-HT4 receptor, suggesting therapeutic potential (36). In another study (38), GF mice were found to have abnormal colonic peristalsis characterized by non-propulsive motility, which was normalized following butyrate administration. Conversely, butyrate did not affect the intestinal contractions of tryptophan hydroxylase-1 (TPH1) knockout (KO) mice (i.e., mice lacking mucosal 5-HT), suggesting that its effect may require mucosal 5-HT. Furthermore, propionate was shown to inhibit propulsive 
contractions in all mice. Gut microbiota may also modify gastrointestinal motility by suppressing the expression of glucagon-like peptide 1 (GLP-1), although the mechanism through which this occurs has yet to be elucidated (39).

Interestingly, a recent investigatory study (40) assessing the effects of Lactobacillus rhamnosus on treating loperamideinduced constipation showed variable degrees of symptomatic improvement which were bacterial strain-specific and independent of the previously reported SCFA effects $(37,38)$. Specifically, L. rhamnosus increased serum peptide YY, colonic 5HT, colonic brain-derived neurotrophic factor, and significantly increased $\alpha$-diversity, with minor effects on improving $\beta$-diversity. Another recent study (41) also used a loperamideinduced constipation mouse model and found that organisms from human breastmilk such as Pediococcus pentosaceus B49 may contribute to marked improvements in intestinal transit time and stool production. Supplementation with $P$. pentosaceus B49 was also associated with significant reductions in pathogenic bacteria at the genus level (Alloprevotella, Staphylococcus, and Helicobacter), and normalization of expression levels of genes involved in gastrointestinal water and ion transport, peristalsis, inflammation, and even malignancies.

Studies in which the microbiome has been perturbed by antibiotics suggest a potential link to intestinal motility. Mice receiving 4 weeks of antibiotic treatment were found to exhibit overall lower intestinal and colonic transit times, as well as decreased levels of lithocholic acid and microbial-derived 5-HT production compared to controls (42). While muscle tension was significantly decreased in the antibiotic-treated group, the frequency of intestinal contractions remained unchanged. Another study assessing antibiotic-induced dysbiosis in juvenile demonstrated similar effects, including delayed gastrointestinal transit, reduced frequency of stool expulsion, and altered intestinal smooth muscle contractility (43).

Perturbations in the gut microbiome might influence intestinal motility through alterations in the enteric nervous system (ENS). Mice with an intact gut microbiome exhibit increased expression of the transcription factor aryl hydrocarbon receptor (AHR) in colonic neurons compared to antibiotictreated mice and GF mice, whose intestinal peristaltic activity is reduced (44). Interestingly, AHR promotes intestinal peristalsis, particularly in the colon, through a bidirectional interaction with the gut microbiome. Moreover, antibiotic-induced dysbiosis can cause significant decreases in cholinergic neurons and overall myenteric neurons, and distortions in glial networks within the myenteric plexus (43). While antibiotic-induced intestinal dysbiosis does not appear to alter the frequency of contractions, an absence of gut microbiota in the perinatal period may affect smooth muscle function. Specifically, GF and altered Schaedler flora (ASF) have been shown to exhibit significant decreases in amplitude and frequency of smooth muscle contractions compared to specific-pathogen free (SPF) mice as early as postnatal day 3 (45). Similar to antibiotic-induced dysbiosis, GF and ASF mice exhibit significant reductions in myenteric neurons and disruptions in nerve fibers within the myenteric plexus (45). Conventionalization of GF mice with SPF flora may rescue the excitability of myenteric neurons (46). Together, these findings indicate an important role for the gut microbiome in facilitating intestinal motility beginning in early life.

The mechanisms through which intestinal bacteria mediate motility via the ENS remain unclear. This interaction was traditionally believed to occur through immune mediators (47). However, increasing evidence supports the role of direct microbiome-enteric neuron interactions. Enteric neurons have been shown to directly express TLRs, with knock-down models demonstrating significant reductions in intestinal motility (4850) and thus exhibiting a constipated phenotype. This suggests that bacteria or bacterial products may interact directly with enteric neurons to facilitate ENS maturation, function, and intestinal motility.

\section{The Gut Microbiome of Children With Constipation}

To date, five studies have investigated the gut microbiome of children with constipation $(51,52)$. Zhu and collaborators (28) carried out the first study using 16s rRNA gene pyrosequencing, finding that obese children with constipation consumed less fiber and had lower levels of Prevotella and increased levels of butyrate-producing taxa (Coprococcus, Roseburia, and Faecalibacterium) than controls. The authors hypothesized that increased butyrate production in constipated children may contribute to the development of the disease, which contradicts other preclinical and adult findings in which butyrate exhibited the opposite effect $(37,38,53,54)$ and that the observed microbiome changes might be the result of a lower fiber intake. It should be noted that no metagenomic analyses were performed and the reported butyrate changes were based on extrapolation of data from other studies that used older techniques to characterize the taxa.

In the most recent study (52), the authors used quantitative real-time polymerase chain reaction ( $\mathrm{qPCR}$ ) to evaluate seven species of Lactobacillus in the fecal samples of 40 children with FC and 40 controls. Constipated children were found to have lower levels of Lactobacillus spp. than controls. However, an important limitation of this study was the omission of an evaluation of dietary intake, which is an important factor influencing the composition of the gut microbiome (55). Similarly, in another study that employed PCR-based analyses, children with constipation were found to have lower levels of Lactobacillus spp. than non-constipated children despite a similar intake of fruits and vegetables, although constipated children consumed more dairy products and junk food (29). Thus, the authors concluded that the lower levels of Lactobacillus spp. might be the result of diet modulation.

Meij et al. (30) prospectively enrolled children with intractable constipation and analyzed their gut microbiomes by using PCR-based analyses, finding microbiome differences from the healthy control group only after employing a ridge regression model: children with constipation had increased abundance of the phyla Proteobacteria, increased levels of Bacteroides spp., Parabacteroides spp., and Bifidobacterium longum, and decreased levels of Alistipes finegoldii and Ruminococcus spp. An important limitation of this study, again, was the fact that dietary intake was not evaluated. 
TABLE 1 | Characteristics of studies assessing the gut microbiota of children with constipation.

\begin{tabular}{|c|c|c|c|c|c|c|c|}
\hline References & Year & Country & Study population & $\begin{array}{l}\text { Microbiota } \\
\text { analysis }\end{array}$ & $\begin{array}{l}\text { Dietary } \\
\text { assessment }\end{array}$ & $\begin{array}{l}\text { Laxative } \\
\text { treatment* }^{\star}\end{array}$ & Findings \\
\hline $\begin{array}{l}\text { Jomehzadeh et al. } \\
\text { (52) }\end{array}$ & 2020 & Iran & $\begin{array}{l}40 \text { children with FC and } \\
40 \text { healthy controls } \\
\text { aged } 4-18 \text { years }\end{array}$ & qPCR & No & No & $\begin{array}{l}\text { Lower levels of Lactobacillus spp. } \\
\text { (L. casei, L. paracasei, L. rhamnosus, } \\
\text { L. plantarum, L. reuteri, L. fermentum, } \\
\text { L. acidophilus) in children with FC children } \\
\text { than controls }\end{array}$ \\
\hline De Meij et al. (30) & 2016 & Netherlands & $\begin{array}{l}76 \text { children with FC and } \\
60 \text { controls aged } 4-18 \\
\text { years }\end{array}$ & $\begin{array}{l}\text { 16S rDNA } \\
\text { sequencing }\end{array}$ & No & No & $\begin{array}{l}\text { Higher levels of Bacteroides spp., } \\
\text { Parabacteroides spp., Bifidobacterium } \\
\text { longum, Proteus mirabilis, and lower levels } \\
\text { of Alistipes finegoldii and Ruminococcus } \\
\text { spp. than controls }\end{array}$ \\
\hline Moraes et al. (29) & 2016 & Brazil & $\begin{array}{l}39 \text { children with FC and } \\
40 \text { controls aged } 6 \\
\text { months to } 3 \text { years }\end{array}$ & qPCR & Yes & Not specified & $\begin{array}{l}\text { Lower levels of Lactobacillus spp, shorter } \\
\text { duration of breastfeeding, and higher rates } \\
\text { of cesarian section in children with FC } \\
\text { than controls }\end{array}$ \\
\hline Zhu et al. (28) & 2014 & USA & $\begin{array}{l}8 \text { constipated obese } \\
\text { children and } 14 \\
\text { controls }\end{array}$ & $\begin{array}{l}\text { 16S rRNA } \\
\text { pyrosequencing }\end{array}$ & Yes & Not specified & $\begin{array}{l}\text { Lower fiber intake and levels of Prevotella, } \\
\text { and increased levels of Coprococcus, } \\
\text { Roseburia and Faecalibacterium in } \\
\text { children with FC than controls }\end{array}$ \\
\hline Zoppi et al. (56) & 1998 & Italy & $\begin{array}{l}28 \text { children with } \\
\text { constipation and } 14 \\
\text { healthy controls aged } \\
5-14 \text { years }\end{array}$ & Culture & Yes & No & $\begin{array}{l}\text { Higher levels of genera Clostridia and } \\
\text { Bifidobacteria in children with FC than } \\
\text { controls }\end{array}$ \\
\hline
\end{tabular}

*Laxative treatment within 4 weeks prior to study.

Finally, a study from 1998 (56) found that children with FC who followed similar Mediterranean diets exhibited higher levels of the genera Clostridia and Bifidobacteria than healthy controls. However, important limitations included the use of culture-dependent approaches which carry a risk of missing bacteria that remain difficult to culture under older laboratory conditions and the omission of assessing dietary adherence. Table 1 summarizes the characteristics of studies assessing the role of the gut microbiome on pediatric FC.

\section{The Gut Microbiome of Adults With Constipation}

The gut microbiome of adults with constipation and slow colonic transit times has also been investigated (57). A 2020 study (54) of adult subjects with long colonic transits - but without constipation - showed that increased $\alpha$-diversity (i.e., the diversity of taxa within a sample/sampled site) was significantly associated with longer descending colon transit time but not with stool consistency. In addition, longer rectosigmoid transit time was associated with low concentrations of fecal SCFAs (butyrate, propionate, valerate, and caproate), while fecal caproate and plasma acetate were associated with longer transit times of the whole colon and descending colon, respectively. Bacteria belonging to the Oscillospira genus may also be implicated in the pathogenesis of constipation in adults (58).

Moreover, Mancabelli et al. (53) conducted a study that employed 16S rRNA sequencing and shotgun metagenomics to study the gut microbiome of adults with and without FC. Non-constipated subjects exhibited significantly higher levels of Bacteroides, Roseburia and Coprococcus, and lower levels of Faecalibacterium than constipated subjects. As the first three are butyrate-producing taxa, the authors hypothesized that the motility-stimulating effect exerted by these SCFAs may "counteract" the development of FC. Furthermore, the metagenomic analysis revealed that non-constipated subjects exhibited a higher abundance of genes involved in carbohydrate and fatty acid metabolism (pathways involved in SCFAs production), while the constipated group had a higher abundance of genes involved in methane production (a gas that delays intestinal transit; see next section). Importantly, both groups consumed similar diets, with non-constipated subjects consuming more sweets, however, this did not reach statistical significance. This is thus far the most informative study as it evaluated the composition and functionality of the gut microbiome of constipated and non-constipated subjects. A further similar study of children would certainly be of great interest.

\section{Methanogenic-Type Small Intestinal Bacterial Overgrowth}

Methane, a biologically active gas mainly produced by members of the domain Archaea (e.g., Methanobrevibacter smithii) as a byproduct of carbohydrate fermentation (59), has been shown to delay intestinal transit in animal and human models (60). There is a subgroup of children with methanogenic-type small intestinal bacterial overgrowth (SIBO) who present with constipation (60) and, importantly, may have additional symptomatology that can help to distinguish them from non-methane producers. For example, symptoms such as retentive fecal incontinence, abdominal pain, flatulence, and bloating are more likely to be present in these children (61-63). Methanogenic-SIBO can 
TABLE 2 | Characteristics of studies assessing the effects of probiotics on children with constipation.

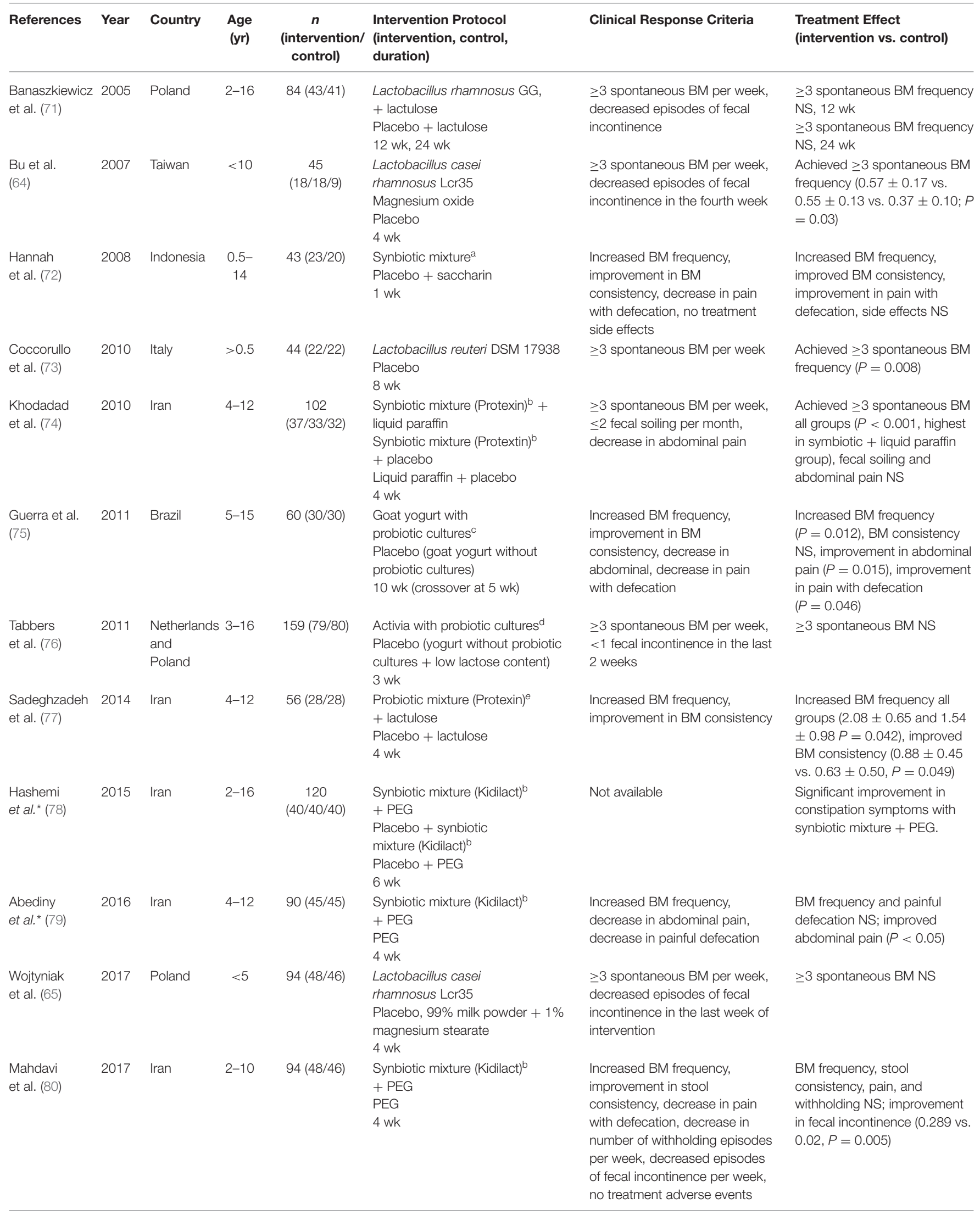


TABLE 2 | Continued

\begin{tabular}{|c|c|c|c|c|c|c|c|}
\hline References & Year & Country & $\begin{array}{l}\text { Age } \\
\text { (yr) }\end{array}$ & $\begin{array}{l}n \\
\text { (intervention/ } \\
\text { control) }\end{array}$ & $\begin{array}{l}\text { Intervention Protocol } \\
\text { (intervention, control, } \\
\text { duration) }\end{array}$ & Clinical Response Criteria & $\begin{array}{l}\text { Treatment Effect } \\
\text { (intervention vs. control) }\end{array}$ \\
\hline $\begin{array}{l}\text { Russo et al. } \\
\text { (81) }\end{array}$ & 2017 & Italy & $4-12$ & $55(27 / 28)$ & $\begin{array}{l}\text { Probiotic mixture }(\text { Tribif })^{f}+\text { PEG } \\
\text { PEG } \\
8 \text { wk }\end{array}$ & $\begin{array}{l}\geq 3 \text { spontaneous BM per week, } \\
\text { increased BM frequency, } \\
\text { improvement in BM consistency } \\
\text { Bristol } \geq \text { grade } 3 \text {, decrease in } \\
\text { abdominal pain, decreased } \\
\text { episodes of fecal incontinence, } \\
\text { decreased rectal bleeding with } \\
\text { defecation }\end{array}$ & $\begin{array}{l}\geq 3 \text { spontaneous BM, BM } \\
\text { frequency, BM consistency, } \\
\text { abdominal pain, fecal } \\
\text { incontinence and rectal } \\
\text { bleeding NS }\end{array}$ \\
\hline $\begin{array}{l}\text { Bastürk } \\
\text { et al. (82) }\end{array}$ & 2017 & Turkey & $4-18$ & $155(77 / 78)$ & $\begin{array}{l}\text { Synbiotic mixtureg }+ \text { prebiotics }^{\text {h }} \\
\text { Placebo } \\
4 \text { wk }\end{array}$ & $\begin{array}{l}\text { Increased BM frequency, } \\
\text { improvement in BM consistency } \\
\text { (Bristol type), decrease in } \\
\text { abdominal pain, decrease in } \\
\text { pain with defecation }\end{array}$ & $\begin{array}{l}\text { Increased BM frequency ( } p \leq \\
0.001) \text {, improvement in } \mathrm{BM} \\
\text { consistency }(p \leq 0.001) \text {, } \\
\text { improvement in abdominal } \\
\text { pain }(p \leq 0.001) \text {, improvement } \\
\text { in pain with defecation ( } p \leq \\
0.001 \text { ) }\end{array}$ \\
\hline $\begin{array}{l}\text { Jose et al. } \\
\text { (83) }\end{array}$ & 201 & India & $<18$ & $60(30 / 30)$ & $\begin{array}{l}\text { Probiotic mixture (Protexin) } \\
+ \text { lactulose } \\
\text { Placebo + lactulose } \\
4 \mathrm{wk}\end{array}$ & $\begin{array}{l}\text { Increased BM frequency, } \\
\text { improvement in BM } \\
\text { consistency, decrease in } \\
\text { abdominal pain, decreased } \\
\text { episodes of fecal incontinence, } \\
\text { no treatment side effects }\end{array}$ & $\begin{array}{l}\text { Increased BM frequency, } \\
\text { improvement in BM } \\
\text { consistency; abdominal pain } \\
\text { and fecal incontinence NS }\end{array}$ \\
\hline $\begin{array}{l}\text { Wegner } \\
\text { et al. ( } 84)\end{array}$ & 2018 & Poland & $3-7$ & $129(65 / 64)$ & $\begin{array}{l}\text { Lactobacillus reuteri DSM } 17938 \\
+ \text { PEG } \\
\text { Placebo + PEG } \\
8 \text { wk }\end{array}$ & $\begin{array}{l}\geq 3 \text { spontaneous BM per week, } \\
\text { increased BM frequency, } \\
\text { improvement in BM } \\
\text { consistency, decrease in pain } \\
\text { with defecation, decreased } \\
\text { episodes of fecal incontinence }\end{array}$ & $\begin{array}{l}\geq 3 \text { spontaneous BM, BM } \\
\text { frequency, BM consistency, } \\
\text { painful defecation and fecal } \\
\text { incontinence NS }\end{array}$ \\
\hline $\begin{array}{l}\text { Jadrešin } \\
\text { et al. (95) }\end{array}$ & 2018 & Croatia & $2-18$ & $33(18 / 15)$ & $\begin{array}{l}\text { L. reuteri DSM } 17938 \text { + lactulose } \\
\text { Placebo + lactulose } \\
12 \text { wk }\end{array}$ & $\begin{array}{l}\text { Increased BM frequency, } \\
\text { improvement in BM } \\
\text { consistency, improvement in } \\
\text { symptoms at the end of the } \\
\text { study, decreased dose of the } \\
\text { lactulose needed, and } \\
\text { decreased episodes of fecal } \\
\text { incontinence }\end{array}$ & $\begin{array}{l}\text { BM frequency, BM } \\
\text { consistency, presence of } \\
\text { symptoms, lactulose and fecal } \\
\text { incontinence NS }\end{array}$ \\
\hline
\end{tabular}

Data extracted from systematic review and meta-analysis by Harris et al. (70) BM, bowel movement; NS, not significant; PEG, polyethylene glycol; RR, relative risk.

a Lactobacillus acidophilus, Lactobacillus rhamnosus, Lactobacillus casei, Lactobacillus bulgaricus, Bifidobacterium infantis, Bifidobacterium breve, Streptococcus thermophiles.

${ }^{b}$ Lactobacillus casei, Lactobacillus rhamnosus, Streptococcus thermophilus, Bifidobacterium breve, Lactobacillus acidophilus, Bifidobacterium infantis, fructooligosaccharide.

${ }^{c}$ Bifidobacterium longum, Lactobacillus delbrueckii subsp. bulgaricus, Streptococcus thermophiles.

${ }^{d}$ Bifidobacterium lactis DN-173010, Lactobacillus delbrueckii subsp. bulgaricus, Streptococcus thermophiles.

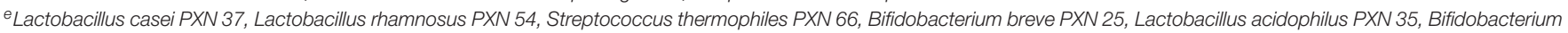
infantis (child specific) PXN 27, and Lactobacillus bulgaricus PXN 39.

${ }^{f}$ Bifidobacterium breve $M-16 \mathrm{~V}$, Bifidobacterium infantis $M-63$, Bifidobacterium longum BB536.

${ }^{9}$ Lactobacillus casei, Lactobacillus rhamnosus, Lactobacillus plantarum, Bifidobacterium lactis.

${ }^{h}$ Fiber, polydextrose, fructo-oligosaccharides, galacto-oligosaccharides.

${ }^{*}$ Full text not available in English.

be diagnosed via the methane/hydrogen breath test and these children may benefit from antibiotic treatment (60).

\section{Microbiota-Based Treatments and Functional Constipation in Children}

One of the main purposes of understanding the gut microbiome of constipated children is to develop therapeutics such as prebiotics, probiotics, and symbiotics, as well as other microbiome-derived motility-promoting interventions. Thus, it is paramount to first understand the composition and functionality of the gut microbiome in children with constipation. Paradoxically, more research has been conducted on the effects of probiotics than on the gut microbiome itself. The latest systematic review (51) assessed eight randomized placebo-controlled trials (RCTs) which investigated the role of various strains of probiotics on the treatment of childhood FC. Only one RCT showed significant improvement in stool frequency and consistency, and reduction in abdominal pain using Lactobacillus casei rhamnosus Lcr35 (64), however, these findings were contradicted by a later trial (65), and the pooled results of the two RCTs showed no statistical significance for treatment success (66). Previous systematic reviews (66-69) 
have also demonstrated insufficient evidence to recommend the use of prebiotics, probiotics, or synbiotics in the treatment of childhood FC, and highlighted important inconsistencies and methodologic errors in prior systematic reviews (70). Table 2 depicts the characteristics of studies assessing the effects of probiotics on children with constipation.

An alternative microbiota-based therapy that is gaining increasing popularity for the treatment of FC is fecal microbiota transplantation (FMT). To date, only one adult RCT (85) has been published and showed a $30 \%$ higher cure rate compared to conventional treatment with laxatives, probiotics, and behavioral training (85). Additional pilot studies demonstrated similar improvements in symptoms and quality of life (86-88) and successful engraftment of donor microbiota (89), with benefits lasting for at least 1-year post-treatment $(88,89)$. No clinical trials have yet been published assessing the role of FMT in the treatment of pediatric FC, however, three trials are currently underway (90-92).

\section{DISCUSSION, CONCLUSION, AND FUTURE DIRECTIONS}

Based on preclinical and clinical evidence, disturbances in the gut microbiome may alter intestinal physiology and motility, and contribute to the development of constipation. However, it is important to mention that the currently available evidence is limited by a paucity of pediatric studies and varying study methodologies. It appears that SCFAs, particularly butyrate, can have a motility promoting effect in both human and animal models, although the evidence is controversial. The role of other molecules in FC, such as 5-HT, bile acids, tryptamine, and GLP-1,

\section{REFERENCES}

1. Koppen IJN, Vriesman MH, Saps M, Rajindrajith S, Shi X, van EttenJamaludin FS, et al. Prevalence of functional defecation disorders in children: a systematic review and meta-analysis. J Pediatr. (2018) 198:121-30.e6. doi: 10.1016/j.jpeds.2018.02.029

2. Vriesman MH, Rajindrajith S, Koppen IJN, van Etten- Jamaludin FS, van Dijk M, Devanarayana NM, et al. Quality of life in children with functional constipation: a systematic review and meta-analysis. J Pediatr. (2019) 214:14150. doi: 10.1016/j.jpeds.2019.06.059

3. Liem O, Harman J, Benninga M, Kelleher K, Mousa H, Di Lorenzo C. Health utilization and cost impact of childhood constipation in the United States. $J$ Pediatr. (2009) 154:258-62. doi: 10.1016/j.jpeds.2008.07.060

4. Rajindrajith S, Devanarayana NM, Perera BJC, Benninga MA. Childhood constipation as an emerging public health problem. World J Gastroenterol. (2016) 22:6864-75. doi: 10.3748/wjg.v22.i30.6864

5. Colombo JM, Wassom MC, Rosen JM. Constipation and encopresis in Childhood. Pediatr Rev. (2015) 36:392-402. doi: 10.1542/pir.36-9-392

6. Benninga MA, Nurko S, Faure C, Hyman PE, St James Roberts I, Schechter NL. Childhood functional gastrointestinal disorders: Neonate/toddler. Gastroenterology. (2016) 150:1443-55e2. doi: 10.1053/j.gastro.2016.02.016

7. Hyams JS, Di Lorenzo C, Saps M, Shulman RJ, Staiano A, Van Tilburg M. Childhood functional gastrointestinal disorders: child/adolescent. Gastroenterology. (2016) 150:1456-68e2. doi: 10.1053/j.gastro.2016.02.015

8. Tabbers MM, Dilorenzo C, Berger MY, Faure C, Langendam MW, Nurko S, et al. Evaluation and treatment of functional constipation in warrants further investigation in human models. Furthermore, diet may be a potential confounder as it can modulate gut bacteria, making it difficult to ascertain causal relationships between the gut microbiome and FC. To date, a gut microbiota signature in children with $\mathrm{FC}$ has not been identified.

The pathophysiology of FC is multifactorial, encompassing a complex interplay between psychological factors, gut microbiota, and gastrointestinal motility. Disruptions to the gut microbiome may contribute to the development and outcome of FC in children. More research is required to elucidate the mechanisms through which the gut microbiome influences intestinal motility and to assess the role of microbiota-based interventions in pediatric FC.

We believe that future studies assessing the gut microbiome in children with FC should: (1) include constipated (withholders and non-withholders) children fulfilling the Rome IV criteria and a control group (93); (2) ensure children are off laxatives at the time of enrollment; (3) evaluate dietary intake as accurately as possible (before [recall] and during the study) (94), as well as early-life gut microbiome insults variables; and, (4) to assess the gut microbiota via, ideally, $16 \mathrm{~S}$ rRNA sequencing, metagenomic shotgun sequencing, and transcriptomics analyses, at the time of enrollment (off-laxative) and then while on treatment (multiple samples) (94).

\section{AUTHOR CONTRIBUTIONS}

DA contributed conception and design of the manuscript. DA and JP wrote the first draft of the manuscript. ET and ER wrote and edited sections of the manuscript. All the authors contributed to manuscript revision, read, and approved the submitted version. infants and children: Evidence-based recommendations from ESPGHAN and NASPGHAN. J Pediatr Gastroenterol Nutr. (2014) 58:258-74. doi: 10.1097/MPG.0000000000000266

9. Bongers MEJ, Van Wijk MP, Reitsma JB, Benninga MA. Long-term prognosis for childhood constipation: clinical outcomes in adulthood. Pediatrics. (2010) 126:e156-62. doi: 10.1542/peds.2009-1009

10. Pijpers MAM, Bongers MEJ, Benninga MA, Berger MY. Functional constipation in children: a systematic review on prognosis and predictive factors. J Pediatr Gastroenterol Nutr. (2010) 50:256-68. doi: 10.1097/MPG.0b013e3181afcdc3

11. Koppen IJN, van Wassenaer EA, Barendsen RW, Brand PL, Benninga MA. Adherence to polyethylene glycol treatment in children with functional constipation is associated with parental illness perceptions, satisfaction with treatment, and perceived treatment convenience. J Pediatr. (2018) 199:1329.e1. doi: 10.1016/j.jpeds.2018.03.066

12. Koppen IJN, Camilleri M, Lorenzo C Di, Benninga MA. Management of functional constipation in children and adults. Nat Rev Gastroenterol Hepatol. (2020) 17:21-39. doi: 10.1038/s41575-019-0222-y

13. LeLeiko NS, Mayer-Brown S, Cerezo C, Plante W. Constipation. Pediatr Rev. (2020) 41:379-92. doi: 10.1542/pir.2018-0334

14. Boronat AC, Ferreira-Maia AP, Matijasevich A, Wang YP. Epidemiology of functional gastrointestinal disorders in children and adolescents: A systematic review. World J Gastroenterol. (2017) 23:3915-27. doi: 10.3748/wjg.v23.i21.3915

15. Ferreira-Maia AP, Matijasevich A, Wang YP. Epidemiology of functional gastrointestinal disorders in infants and toddlers: A systematic review. 
World J Gastroenterol. (2016) 22:6547-58. doi: 10.3748/wjg.v22.i2 8.6547

16. Mugie SM, Benninga MA, Di Lorenzo C. Epidemiology of constipation in children and adults: a systematic review. Best Pract Res Clin Gastroenterol. (2011) 25:3-18. doi: 10.1016/j.bpg.2010.12.010

17. Walter AW, Hovenkamp A, Devanarayana NM, Solanga R, Rajindrajith S, Benninga MA. Functional constipation in infancy and early childhood: Epidemiology, risk factors, and healthcare consultation. BMC Pediatr. (2019) 19:1-10. doi: 10.1186/s12887-019-1652-y

18. Philips EM, Peeters B, Teeuw AH, Leenders AGE, Boluyt N, BrilleslijperKater SN, et al. Stressful life events in children with functional defecation disorders. J Pediatr Gastroenterol Nutr. (2015) 61:384-92. doi: 10.1097/MPG.0000000000000882

19. Oswari H, Alatas FS, Hegar B, Cheng W, Pramadyani A, Benninga MA, et al. Epidemiology of Paediatric constipation in Indonesia and its association with exposure to stressful life events. BMC Gastroenterol. (2018) 18:1-8. doi: 10.1186/s12876-018-0873-0

20. Froon-Torenstra D, Beket E, Khader AM, Hababeh M, Nasir A, Seita A, et al. Prevalence of functional constipation among Palestinian preschool children and the relation to stressful life events. PLoS ONE. (2018) 13:1-9. doi: 10.1371/journal.pone.0208571

21. Joinson C, Grzeda MT, von Gontard A, Heron J. Psychosocial risks for constipation and soiling in primary school children. Eur Child Adolesc Psychiatry. (2019) 28:203-10. doi: 10.1007/s00787-018-1162-8

22. Beaudry-Bellefeuille I, Booth D, Lane SJ. Defecation-specific behavior in children with functional defecation issues: a systematic review. Perm J. (2017) 21:1-8. doi: 10.7812/TPP/17-047

23. Avelar Rodriguez D, Peña Vélez R, Toro Monjaraz EM, Ramirez Mayans J, Ryan PM. The gut microbiota: a clinically impactful factor in patient health and disease. SN Compr Clin Med. (2018) 1:188-99. doi: 10.1007/s42399-018-0036-1

24. Stiemsma LT, Michels KB. The role of the microbiome in the developmental origins of health and disease. Pediatrics. (2018) 141:e20172437. doi: 10.1542/peds.2017-2437

25. Hollister EB, Oezguen N, Chumpitazi BP, Luna RA, Weidler EM, RubioGonzales $\mathrm{M}$, et al. Leveraging human microbiome features to diagnose and stratify children with irritable bowel syndrome. J Mol Diagnostics. (2019) 21:449-61. doi: 10.1016/j.jmoldx.2019.01.006

26. Rigsbee L, Agans R, Shankar V, Kenche H, Khamis HJ, Michail S, et al. Quantitative profiling of gut microbiota of children with diarrheapredominant irritable bowel syndrome. Am J Gastroenterol. (2012) 107:174051. doi: 10.1038/ajg.2012.287

27. Saulnier DM, Riehle K, Mistretta TA, Diaz MA, Mandal D, Raza $\mathrm{S}$, et al. Gastrointestinal microbiome signatures of pediatric patients with irritable bowel syndrome. Gastroenterology. (2011) 141:1782-91. doi: 10.1053/j.gastro.2011.06.072

28. Zhu L, Liu W, Alkhouri R, Baker RD, Bard JE, Quigley EM, et al. Structural changes in the gut microbiome of constipated patients. Physiol Genomics. (2014) 46:679-86. doi: 10.1152/physiolgenomics.00082.2014

29. Moraes JG de, Motta MEF de A, Beltrão MF de S, Salviano TL, Silva GAP da. Fecal microbiota and diet of children with chronic constipation. Int J Pediatr. (2016) 2016:1-8. doi: 10.1155/2016/6787269

30. De Meij TGJ, De Groot EFJ, Eck A, Budding AE, Kneepkens CMF, Benninga $\mathrm{MA}$, et al. Characterization of microbiota in children with chronic functional constipation. PLoS ONE. (2016) 11:1-13. doi: 10.1371/journal.pone.0164731

31. Dominguez-Bello MG, Costello EK, Contreras M, Magris M, Hidalgo G, Fierer N, et al. Delivery mode shapes the acquisition and structure of the initial microbiota across multiple body habitats in newborns. Proc Natl Acad Sci U S A. (2010) 107:11971-5. doi: 10.1073/pnas.1002601107

32. Praveen P, Jordan F, Priami C, Morine MJ. The role of breast-feeding in infant immune system: a systems perspective on the intestinal microbiome. Microbiome. (2015) 3:41. doi: 10.1186/s40168-015-0104-7

33. Bäckhed F, Roswall J, Peng Y, Feng Q, Jia H, Kovatcheva-Datchary P, et al. Dynamics and stabilization of the human gut microbiome during the first year of life. Cell Host Microbe. (2015) 17:690-703. doi: 10.1016/j.chom.2015.04.004

34. Vandenplas Y, Carnielli VP, Ksiazyk J, Luna MS, Migacheva N, Mosselmans JM, et al. Factors affecting early-life intestinal microbiota development. Nutrition. (2020) 78:110812. doi: 10.1016/j.nut.2020.110812
35. Chen SM, Huang JY, Wu MC, Chen JY. The risk of developing constipation after neonatal necrotizing enterocolitis. Front Pediatr. (2020) 8:1-8. doi: 10.3389/fped.2020.00120

36. Bhattarai Y, Williams BB, Battaglioli EJ, Fischbach MA, Farrugia G, Kashyap PC, et al. Gut microbiota-produced tryptamine activates an epithelial gprotein-coupled receptor to increase colonic secretion article gut microbiotaproduced tryptamine activates an epithelial g-protein-coupled receptor to increase colonic secretion. Cell Host Microbe. (2018) 23:775-85.e5. doi: 10.1016/j.chom.2018.05.004

37. Dass NB, John AK, Bassil AK, Crumbley CW, Shehee WR, Maurio FP, et al. The relationship between the effects of short-chain fatty acids on intestinal motility in vitro and GPR43 receptor activation. Neurogastroenterol Motil. (2007) 19:66-74. doi: 10.1111/j.1365-2982.2006.00853.x

38. Vincent AD, Wang XY, Parsons SP, Khan WI, Huizinga JD. Abnormal absorptive colonic motor activity in germ-free mice is rectified by butyrate, an effect possibly mediated by mucosal serotonin. Am J Physiol - Gastrointest Liver Physiol. (2018) 315:G896-907. doi: 10.1152/ajpgi.00237.2017

39. Yang M, Fukui H, Eda H, Xu X, Kitayama Y, Hara K, et al. Involvement of gut microbiota in association between GLP-1/GLP-1 receptor expression and gastrointestinal motility. Am J Physiol - Gastrointest Liver Physiol. (2017) 312:G367-73. doi: 10.1152/ajpgi.00232.2016

40. Wang G, Yang S, Sun S, Si Q, Wang L, Zhang Q, et al. Lactobacillus rhamnosus strains relieve loperamide-induced constipation via different pathways independent of short-chain fatty acids. Front Cell Infect Microbiol. (2020) 10:1-14. doi: 10.3389/fcimb.2020.00423

41. Huang J, Li S, Wang Q, Guan X, Qian L, Li J, et al. Pediococcus pentosaceus B49 from human colostrum ameliorates constipation in mice. Food Funct. (2020) 11:5607-20. doi: 10.1039/D0FO00208A

42. Ge X, Ding C, Zhao W, Xu L, Tian H, Gong J, et al. Antibioticsinduced depletion of mice microbiota induces changes in host serotonin biosynthesis and intestinal motility. J Transl Med. (2017) 15:1-9. doi: 10.1186/s12967-016-1105-4

43. Caputi V, Marsilio I, Filpa V, Cerantola S, Orso G, Bistoletti M, et al. Antibiotic-induced dysbiosis of the microbiota impairs gut neuromuscular function in juvenile mice. $\mathrm{Br} J$ Pharmacol. (2017) 174:3623-39. doi: 10.1111/bph.13965

44. Obata Y, Castaño Á, Boeing S, Bon-Frauches AC, Fung C, Fallesen T, et al. Neuronal programming by microbiota regulates intestinal physiology. Nature. (2020) 578:284-9. doi: 10.1038/s41586-020-1975-8

45. Collins J, Borojevic R, Verdu EF, Huizinga JD, Ratcliffe EM. Intestinal microbiota influence the early postnatal development of the enteric nervous system. Neurogastroenterol Motil. (2014) 26:98-107. doi: 10.1111/nmo.12236

46. Mcvey Neufeld KA, Mao YK, Bienenstock J, Foster JA, Kunze WA. The microbiome is essential for normal gut intrinsic primary afferent neuron excitability in the mouse. Neurogastroenterol Motil. (2013) 25:183-90. doi: $10.1111 / \mathrm{nmo} .12049$

47. Bueno L. Neuroimmune alterations of ENS functioning. Gut. (2000) 47(Suppl. 4):63-5. doi: 10.1136/gut.47.suppl_4.iv63

48. Caputi V, Marsilio I, Cerantola S, Roozfarakh M, Lante I, Galuppini F, et al. Toll-like receptor 4 modulates small intestine neuromuscular function through nitrergic and purinergic pathways. Front Pharmacol. (2017) 8:1-15. doi: 10.3389/fphar.2017.00350

49. Brun P, Giron MC, Qesari M, Porzionato A, Caputi V, Zoppellaro C, et al. Toll-like receptor 2 regulates intestinal inflammation by controlling integrity of the enteric nervous system. Gastroenterology. (2013) 145:1323-33. doi: 10.1053/j.gastro.2013.08.047

50. Anitha M, Vijay-Kumar M, Sitaraman SV, Gewirtz AT, Srinivasan S. Gut microbial products regulate murine gastrointestinal motility via toll-like receptor 4 signaling. Gastroenterology. (2012) 143:1006-16.e4. doi: $10.1053 /$ j.gastro.2012.06.034

51. Gomes DOVS, Morais MB. Gut microbiota and the use of probiotics in constipation in children and adolescents: systematic review. Rev Paul Pediatr. (2020) 38:e2018123. doi: 10.1590/1984-0462/2020/38/20 18123

52. Jomehzadeh $\mathrm{N}$, Javaherizadeh $\mathrm{H}$, Amin $\mathrm{M}$, Rashno $\mathrm{M}$, Teimoori A. Quantification of intestinal lactobacillus species in children with functional constipation by quantitative real-time PCR. Clin Exp Gastroenterol. (2020) 13:141-50. doi: 10.2147/CEG.S250755 
53. Mancabelli L, Milani C, Lugli GA, Turroni F, Viappiani A, Ticinesi A, et al. Unveiling the gut microbiota composition and functionality associated with constipation through metagenomic analyses. Sci Rep. (2017) 7:1-9. doi: 10.1038/s41598-017-10663-w

54. Müller M, Hermes GDA, Canfora EE, Smidt H, Masclee AAM, Zoetendal EG, et al. Distal colonic transit is linked to gut microbiota diversity and microbial fermentation in humans with slow colonic transit. Am J Physiol - Gastrointest Liver Physiol. (2020) 318:G361-9. doi: 10.1152/ajpgi.00283.2019

55. Herman DR, Rhoades N, Mercado J, Argueta P, Lopez U, Flores GE. Dietary habits of 2- to 9-year-old American children are associated with gut microbiome composition. J Acad Nutr Diet. (2020) 120:517-34. doi: 10.1016/j.jand.2019.07.024

56. Zoppi G, Cinquetti M, Luciano A, Benini A, Muner A, Bertazzoni Minelli E. The intestinal ecosystem in chronic functional constipation. Acta Paediatr Int J Paediatr. (1998) 87:836-41. doi: 10.1111/j.1651-2227.1998.tb01547.x

57. Ohkusa T, Koido S, Nishikawa Y, Sato N. Gut microbiota and chronic constipation: a review and update. Front Med. (2019) 6:1-9. doi: 10.3389/fmed.2019.00019

58. Chen Y-r, Zheng H-m, Zhang G-x, Chen F-l, Chen L-d, Yang Zc. High Oscillospira abundance indicates constipation and low BMI in the Guangdong Gut Microbiome Project. Sci Rep. (2020) 10:1-8. doi: 10.1038/s41598-020-66369-z

59. Smith NW, Shorten PR, Altermann EH, Roy NC, Warren C, Smith NW. Hydrogen cross-feeders of the human gastrointestinal tract Hydrogen crossfeeders of the human gastrointestinal tract. Gut Microbes. (2018) 10:1-19. doi: 10.1080/19490976.2018.1546522

60. Avelar Rodriguez D, Ryan PMD, Toro Monjaraz EM, Ramirez Mayans JA, Quigley EM. Small Intestinal Bacterial Overgrowth in Children: A State-ofthe-Art Review. Vol. 7, Frontiers in Pediatrics. Frontiers Media S.A. (2019). doi: $10.3389 /$ fped.2019.00363

61. Leiby A, Mehta D, Gopalareddy V, Jackson-walker S, Horvath K. Bacterial overgrowth and methane production in children with encopresis. J Pediatr. (2010) 156:766-70. doi: 10.1016/j.jpeds.2009.10.043

62. Ojetti V, Bruno G, Paolucci V, Triarico S, D'aversa F, Ausili E, et al. The prevalence of small intestinal bacterial overgrowth and methane production in patients with myelomeningocele and constipation. Spinal Cord. (2014) 52:61-4. doi: 10.1038/sc.2013.131

63. Fontenele-Soares AC, Lederman HM, Fagundes-Neto U, Morais MB de. Breath methane associated with slow colonic transit time in children with chronic constipation. J Clin Gastroenterol. (2005) 39:512-5. doi: 10.1097/01.mcg.0000165665.94777.bd

64. Bu LN, Chang MH, Ni YH, Chen HL, Cheng CC. Lactobacillus casei rhamnosus Lcr35 in children with chronic constipation. Pediatr Int. (2007) 49:485-90. doi: 10.1111/j.1442-200X.2007.02397.x

65. Wojtyniak K, Horvath A, Dziechciarz P, Szajewska H. Lactobacillus casei rhamnosus Lcr35 in the management of functional constipation in children: a randomized trial. J Pediatr. (2017) 184:101-105.e1. doi: 10.1016/j.jpeds.2017.01.068

66. Wojtyniak K, Szajewska H. Systematic review: probiotics for functional constipation in children. Eur J Pediatr. (2017) 176:1155-62. doi: 10.1007/s00431-017-2972-2

67. Tabbers MM, Boluyt N, Berger MY, Benninga MA. Nonpharmacologic treatments for childhood constipation: Systematic review. Pediatrics. (2011) 128:753-61. doi: 10.1542/peds.2011-0179

68. Korterink JJ, Ockeloen L, Benninga MA, Tabbers MM, Hilbink M, DeckersKocken JM. Probiotics for childhood functional gastrointestinal disorders: a systematic review and meta-analysis. Acta Paediatr Int J Paediatr. (2014) 103:365-72. doi: 10.1111/apa.12513

69. Wegh CAM, Benninga MA, Tabbers MM. Effectiveness of probiotics in children with functional abdominal pain disorders and functional constipation a systematic review. J Clin Gastroenterol. (2018) 52:S10-26. doi: 10.1097/MCG.0000000000001054

70. Harris RG, Neale EP, Ferreira I. When poorly conducted systematic reviews and meta-analyses can mislead: a critical appraisal and update of systematic reviews and meta-analyses examining the effects of probiotics in the treatment of functional constipation in children. Am J Clin Nutr. (2019) 110:177-95. doi: 10.1093/ajcn/nqz071
71. Banaszkiewicz A, Szajewska H. Ineffectiveness of Lactobacillus GG as an adjunct to lactulose for the treatment of constipation in children: a doubleblind, placebo-controlled randomized trial. J Pediatr. (2005) 146:364-9. doi: $10.1016 /$ j.jpeds.2004.10.022

72. Hannah MJ, Soenarto SY. Effectiveness of synbiotics as laxative agent for constipation in children. Paediatr Indonediana. (2008) 48:136-41. doi: $10.14238 / \mathrm{pi} 48.3 .2008 .136-41$

73. Coccorullo P, Strisciuglio C, Martinelli M, Miele E, Greco L, Staiano A. Lactobacillus reuteri (DSM 17938) in infants with functional chronic constipation: a double-blind, randomized, placebo-controlled study. J Pediatr. (2010) 157:598-602. doi: 10.1016/j.jpeds.2010.04.066

74. Khodadad A, Sabbaghian M. Role of synbiotics in the treatment of childhood constipation: a double-blind randomized placebo controlled trial. Iran J Pediatr. (2010) 20:387-92.

75. Guerra PVP, Lima LN, Souza TC, Mazochi V, Penna FJ, Silva AM, et al. Pediatric functional constipation treatment with bifidobacterium-containing yogurt: a crossover, double-blind, controlled trial. World J Gastroenterol. (2011) 17:3916-21. doi: 10.3748/wjg.v17.i34.3916

76. Tabbers MM, Chmielewska A, Roseboom MG, Crastes N, Perrin C, Reitsma JB, et al. Fermented milk containing Bifidobacterium lactis DN-173 010 in childhood constipation: a randomized, double-blind, controlled trial. Pediatrics. (2011) 127:e1392-9. doi: 10.1542/peds.2010-2590

77. Sadeghzadeh M, Rabieefar A, Khoshnevisasl P, Mousavinasab N, Eftekhari K. The effect of probiotics on childhood constipation: a randomized controlled double blind clinical trial. Int J Pediatr. (2014) 2014:1-5. doi: $10.1155 / 2014 / 937212$

78. Hashemi M, Javaheri J, Habibi M, Yousefichaijan P, Naziri M. Comparing the effect of probiotics and polyethylene glycol in treatment of children with functional constipation. Arak Med Univ J. (2015) 18:78-85.

79. Abediny M, Ataiee P, Afkhamzadeh A, Seifmanesh M, Sedaghat B. The effect of probiotics on the treatment of functional constipation in children of 4-12 years of age. J ISFAHAN Med Sch. (2016) 33:2448-54.

80. Mahdavi M, Esmaeili Dooki MR, Mehrabani S, Hajiahmadi M, Moghadamnia AA, Moslemi L. The effect of adding synbiotics to polyethylene glycol in childhood functional constipation: a randomized clinical trial study. Int J Pediatr. (2017) 5:5357-67.doi: 10.22038/IJP.2017.23141.1990

81. Russo M, Giugliano FP, Quitadamo P, Mancusi V, Miele E, Staiano A. Efficacy of a mixture of probiotic agents as complementary therapy for chronic functional constipation in childhood. Ital J Pediatr. (2017) 43:1-7. doi: 10.1186/s13052-017-0334-3

82. Baştürk A, Artan R, Atalay A, Yilmaz A. Investigation of the efficacy of synbiotics in the treatment of functional constipation in children: a randomized double-blind placebo-controlled study. Turkish J Gastroenterol. (2017) 28:388-93. doi: 10.5152/tjg.2017.17097

83. Jose S, K. MI. Effect of probiotics on constipation in children. Int J Contemp Pediatr. (2017) 5:46. doi: 10.18203/2349-3291.ijcp20175506

84. Wegner A, Banaszkiewicz A, Kierkus J, Landowski P, Korlatowicz-Bilar A, Wiecek S, et al. The effectiveness of Lactobacillus reuteri DSM 17938 as an adjunct to macrogol in the treatment of functional constipation in children. A randomized, double-blind, placebo-controlled, multicentre trial. Clin Res Hepatol Gastroenterol. (2018) 42:494-500. doi: 10.1016/j.clinre.2018.03.008

85. Tian H, Ge X, Nie Y, Yang L, Ding C, McFarland L V, et al. Fecal microbiota transplantation in patients with slow-transit constipation: A randomized, clinical trial. PLoS ONE. (2017) 12:1-10. doi: 10.1371/journal.pone.0171308

86. Ge X, Tian H, Ding C, Gu L, Wei Y, Gong J, et al. Fecal microbiota transplantation in combination with soluble dietary fiber for treatment of slow transit constipation: a pilot study. Arch Med Res. (2016) 47:236-42. doi: 10.1016/j.arcmed.2016.06.005

87. Tian H, Ding C, Gong J, Ge X, Mcfarland L V, Gu L, et al. Treatment of slow transit constipation with fecal microbiota transplantation. J Clin Gastroenterol. (2016) 50:865-70. doi: 10.1097/MCG.0000000000000472

88. Zhang X, Tian H, Gu L, Nie Y, Ding C, Ge X, et al. Long-term follow-up of the effects of fecal microbiota transplantation in combination with soluble dietary fiber as a therapeutic regimen in slow transit constipation. Sci China Life Sci. (2018) 61:779-86. doi: 10.1007/s11427-017-9229-1

89. Ohara T. Identification of the microbial diversity after fecal microbiota transplantation therapy for chronic intractable constipation using 
16s rRNA amplicon sequencing. PLoS ONE. (2019) 14:1-12. doi: 10.1371/journal.pone. 0214085

90. Fecal Microbiota Transplantation for Constipation (NCT03308461). U.S. National Library of Medicine: Clinical Trials.

91. Safety and Efficacy of Fecal Microbiota Transplantation (NCT04014413). U.S. National Library of Medicine: Clinical Trials.

92. MTT for Children with ASD Who Have Gastrointestinal Disorders. (NCT04182633). U.S. National Library of Medicine: Clinical Trials.

93. Koppen IJN, Saps M, Lavigne JV., Nurko S, Taminiau JAJM, Di Lorenzo C, et al. Recommendations for pharmacological clinical trials in children with functional constipation: the Rome foundation pediatric subcommittee on clinical trials. Neurogastroenterol Motil. (2018) 30:1-10. doi: 10.1111/nmo.13294

94. Johnson AJ, Zheng JJ, Kang JW, Saboe A, Knights D, Zivkovic AM. A guide to diet-microbiome study design. Front Nutr. (2020) 7:1-16. doi: $10.3389 /$ fnut. 2020.00079
95. Jadrešin O, Sila $S$, Trivić I, Mišak Z, Hojsak I, Kolaček S. Lack of benefit of Lactobacillus reuteri DSM 17938 as an addition to the treatment of functional constipation. J Pediatr Gastroenterol Nutr. (2018) 67:763-6. doi: 10.1097/MPG.0000000000002134

Conflict of Interest: The authors declare that the research was conducted in the absence of any commercial or financial relationships that could be construed as a potential conflict of interest.

Copyright $\odot 2021$ Avelar Rodriguez, Popov, Ratcliffe and Toro Monjaraz. This is an open-access article distributed under the terms of the Creative Commons Attribution License (CC BY). The use, distribution or reproduction in other forums is permitted, provided the original author(s) and the copyright owner(s) are credited and that the original publication in this journal is cited, in accordance with accepted academic practice. No use, distribution or reproduction is permitted which does not comply with these terms. 